\title{
State defense during the first wave of the COVID- 19 pandemic: the cases of the Russian Federation and Hungary
}

\author{
Kristina Krasnova $^{1}$, Maria Reshnyak $^{2, *}$, Vince Vári $^{3}$ \\ ${ }^{1}$ Russian State University of Justice North-Western branch, Saint Petersburg, Russia \\ ${ }^{2}$ Moscow State Institute of International Relations (University) of the Ministry of Foreign Affairs \\ Russian Federation (MGIMO University), Moscow, Russia \\ ${ }^{3}$ University of Public Service (Budapest, Hungary), Budapest, Hungary
}

\begin{abstract}
The first cases of the COVID-19 epidemic, registered in January 2020, and the first wave that followed, hit the world unprepared. The only means available to the various states were the various restrictive measures expected to alleviate the epidemic. In this article, the restrictive legal measures of two European countries, the EU member state Hungary and non-the EU member state Russia, are compared from the rule of law and law enforcement. The special legal order introduced in both countries and the measures taken within its framework have resulted in a significant restriction of fundamental rights. The epidemiological data of the two countries differed significantly, yet they tried very hard to defend themselves with similar means. There are two primary differences. Russia has used more robust control mechanisms to enforce similar measures, presumably due to the more difficult epidemic situation. The other difference is that Russia's restrictions against Hungary did not cover freedom of expression and freedom of expression. As both the state of emergency and, with it, the more severe restrictions were lifted during the period under review. Following the reduction of the epidemic situation, both states remained within the legal framework.
\end{abstract}

\section{Introduction}

The first news of the COVID-19 pandemic arrived on the European continent in January 2020. The WHO declared COVID-19 a public health emergency of international concern on 30 January and an epidemic on 11 March 2020 (Balkhair 2020). Recognition of the situation was greatly hampered by the fact that the disease symptoms were sufficiently uncertain, in many cases not occurring at all. In the mostly country, the disease appeared long before it could be detected (Singhal 2020). Because of this, different governments were only able to respond late (Andreson et al., 2020). In the first period of the epidemic, all countries watched China, from where the epidemic started. Vaccination or medication did not exist at that time. Therefore, the current state has introduced restrictive measures to mitigate the effects of the

\footnotetext{
*Corresponding author: irbis-7375@yandex.ru
} 
epidemic. These were intended to reduce the chances of transmission of the infection. The period we examined emphatically covers the time of the first wave of the epidemic. As it was published at a slightly variable time in each country, we analyze the period from 1 January to 1 June 2020. This period was mainly since many restrictive measures were lifted in a short time, mainly in June.

Research shows that society tends to accept restrictions where people are more harmed by the epidemic (Meier et al. 2020). Examining the issue from the point of view of voluntary compliance, a hypothetical conclusion can be drawn. First, one factor in responsible social behavior is the severity of the epidemic. And where the epidemic was milder, people have little identification with the restrictions. The second conclusion is based on the assumption that the limits are of a different preventive nature, so the effectiveness of implementation cannot depend on the severity of the epidemic. Therefore, the practical implementation may require the direct application of public authority. One of the tools for this is official measures to ensure law enforcement (Balla 2009). The effectiveness of protection based on voluntary compliance is strongly influenced by government communication, access to accurate information, and the development of a given society, which is reflected in conscious civic behavior (Wolf et al. 2020). The lack or existence of knowledge does not depend on people's health status, so it cannot be said that members of a higher risk for an epidemic would be better informed. Therefore, awareness and adherence to epidemiological rules require dependence on the most critical factors in terms of attitude (Georghe et al. 2020). Everyone in society does not voluntarily follow regulations due to lack of information, false information, incomplete government communication, or just the generally low level of health awareness. In this case, the law enforcement-type government interventions are given more space.

We examine the limited preventive measures used in the first wave of the COVID-19 pandemic in the countries under investigation and the extent to which their implementation relied on the responsible behavior of the population based on voluntary compliance and the means of government. Finally, we provide a brief overview of specific public law instruments for the conservation of medical supplies. These all differ from the system of health administration and its strong audience, as well as from the law enforcement-type regulation implemented in the country in the traditional sense.

\section{Methodology}

We are examining the restrictive measures of two countries, Russia and Hungary. In order to find out the epidemiological data, we contacted the police authorities of the two states. We were assisted in this by liaison officers who facilitated cooperation between the police forces of the two states. The first confirmed infection occurred in Hungary on March 4, 2020, and in Russia on March 1, 2020. However, there were significant differences in the epidemiological data because of population. The political and legal situation of the two states differs in that Hungary is a member of the EU, and the Russian Federation is a non-member of the EU (Tihanyi et al. 2020).

The comparison within the framework of the article is limited to the public law framework of epidemiological control. Accordingly, we examine legislative processes whose declared purpose was to control the epidemic. We reviewed the restrictive measures applied by the governments of the countries studied. These measures are followed mainly by the Centers for Disease Control and Prevention during the 2003 SARS epidemic. (URL 1) We then grouped these implemented actions according to their direction. The following recommendations have been identified. The first is the level of personal protection, including personal protective equipment and social distance. The second is tools to alleviate mass infection within the country. Most of these are restrictive provisions that work against group 
formations. This measure includes the introduction of curfews, the closure of schools, workplaces, other grouping places (eg, sports, cultural, entertainment venues), and the banning of gatherings. Finally, the direction of protection against infections from abroad emerges. These include the quarantine of citizens returning from abroad, exit and entry bans, and the partial closure of borders. One way to reduce people-to-people contacts is to reduce available mobility goals. Early closure of shops, closure of group-forming sites, and similar measures reduce mobility and the number of people-to-people connections. All this was available to governments as the only means to reduce the number of infections in the first wave of the epidemic. Research to date has shown that there have been demonstrable benefits in complying with these rules (Hadjidemetriou et al.). Therefore, the restrictive provisions that states make and the level they are complied with were of particular importance for defense and prevention.

One of the most basic levels of social protection was individual protection. The success of this depends mainly on the attitudes of individuals. Those with more information and greater health literacy tend to follow the rules of personal defense better. Somewhat surprisingly, various restrictive measures are generally better accepted and supported. (Selby et al. 2020).

In each case, a legal comparison of different states also means a comparison of other legal systems. One of the difficulties arising from this is the marking and reference of legal sources. In the present case, we chose the solution that we used the standard format of concern in the given state; therefore, the connection of the Hungarian and Russian legal sources is different - thus more distinguishable.

\section{The role of a special legal order in defense}

The COVID-19 pandemic, unfortunately, has affected virtually every nation in the world (Salikov 2020). An exceptional legal order is a state framework for dealing with a social or natural phenomenon that cannot be managed in the state's normal state and that endangers people, the state, or the constitutional order. Its purpose is to maintain the efficiency of the operation of the state for a transitional period. An additional goal can be to develop a security and protection system that ensures the performance of tasks that arise during emergencies. The elimination of dangers for which the "ordinary" operation of the state the organizational structure is unsuitable or for which the administrative and operational conditions are unsuitable must be implemented.

The characteristic of an emergency compared to other special legal situations is that it is not aimed at the armed defense of the state. According to Article 53 of the Basic Law of Hungary, the Government declares a state of emergency in the event of an elemental disaster or industrial accident endangering the safety of life and property. It may prevent emergency measures specified in a cardinal law. As specified in a cardinal rule, it may suspend the application of specific laws, deviate from statutory provisions, and take other extraordinary measures. Government regulations automatically expire when the emergency ceases. In a special legal order, including in times of crisis, the exercise of fundamental rights may be restricted or suspended. Exceptions are the right to life and human dignity and torture, inhuman or degrading treatment, servitude, trafficking in human beings, medical or scientific experimentation without consent, human breeding practices, exploitation of the human body and its parts (organ trafficking). ) and the prohibition of human reproduction (cloning). Exceptions are also the presumption of innocence, the right to a defense in criminal proceedings, the principle of 'nullum crimen sine lege,' the principle of 'nulla poena sine lege,' and the principle of 'one bis in idem.

In an emergency, the principle of the separation of powers must necessarily, but only temporarily, suffer. As the head of the executive branch, the government also has a sizeable 
legislative function during such a period. At the same time, it is essential that the government with expanded power exercise due to restraint during this period. The emergency in Hungary was first declared on March 11, 2020. At the same time, the National Assembly authorized the government to regulate the country's life even in decrees in times of emergency, which deviate from the laws at the higher level of legal sources. These regulations made it possible to suspend the validity of specific rules. Using the mandate, the government issued nearly 300 decrees, some of which aimed to protect the economy and others aimed at controlling the epidemic.

The emergency was lifted on 18 June 2020. At the same time, a health crisis epidemiological preparedness was announced. ${ }^{1}$ However, this can no longer be considered an extraordinary legal order ${ }^{2}$.

The presence of the COVID-19 virus has brought about a number of changes in the functioning of the competent state bodies and institutions, as well as in the functioning of its citizens in the Russian Federation as well.

According to Part 2 of Art. 56 of the Constitution of the Russian Federation, a state of emergency throughout the country and in its individual areas may be introduced in presence of the circumstances and in accordance with the procedure established by Federal Constitutional Law of 30.05.2001 No. 3-ФК3 "On the state of emergency". This law defines a state of emergency as a special legal regime of operation of federal government authorities, local government authorities, organizations, regardless of their type and form of ownership, their officials, public associations, allowing individual restrictions on the rights and freedoms of citizens, foreign citizens, stateless persons, the rights of organizations and public associations, as well as the imposition of additional responsibilities on them. The imposition of a state of emergency is a temporary measure applied exclusively to ensure the safety of citizens and the protection of the constitutional order. Emergencies are divided into different levels depending on the number of people affected and the amount of damage caused. Although the exponential growth in the incidence of the disease in the spring of 2020 was spread throughout the country, the state of emergency was not introduced and, thus, the top state bodies retained all their powers. During this period, the following Presidential Decrees were issued: Presidential Decree as of 25 March 2020 No. 206 "On the announcement of non-working days in the Russian Federation", Presidential Decree as of 2 April 2020 No. 239 "On measures to ensure the sanitary and epidemiological well-being of the population in the Russian Federation in connection with the spread of the new coronavirus infection (COVID-19) ", Presidential Decree as of 28.04.2020 No. 294 "On the extension of measures to ensure the sanitary and epidemiological well-being of the population in the Russian Federation in connection with the spread of the new coronavirus infection (COVID-19)". At the same time, almost all legislative and executive bodies, judicial and law enforcement agencies at the beginning of the period of introducing quarantine measures were not ready for consistent full-scale operation (Reshnyak 2020).

The relationship between the federal center and the constituent entities of the federation in such an extraordinary situation has been affected too and has undergone certain changes. Their analysis cannot but lead to a correction of the normative regulation of federal relations in the event of similar situations in the future. Subsequently, amendments to the Constitution of the Russian Federation from 1 July, 2020 have affected a large layer of public relations (Salikov 2020).

${ }^{1}$ 282/2020. (IV. 17.) Government decree

2 283/2020. (IV. 17.) Government decree 


\section{Restrictions}

In order to defend themselves, the right of citizens to free movement and the freedom of assembly had to be restricted the most. Both restrictive measures were aimed at minimizing personal encounters between people. Thus, it was hoped that those infected would continue to infect fewer people, thereby slowing the spread of the epidemic. It was also aimed at closing shops, nightclubs, cultural institutions, public and higher education institutions.

The restriction on the right to free movement was the introduction of exit restrictions. Accordingly, goals and activities were defined that people could leave their residential properties to achieve or perform. In all other cases, it was forbidden to leave the apartment. It should be noted that the exceptions to the curfew provided such a broad framework of interpretation that compliance with the rules was essentially voluntary compliance. Violators of the curfew committed an offense and had to be dealt with by the police. Still, the numerous exceptions and the means of proving the right of curfew presented the authority with a significant burden of proof. ${ }^{3}$ The same applies to quarantine rules. Based on these, those arriving in Hungary from abroad, the certified infected Hungarian citizens, and the persons in direct contact with them had to stay in the designated place (quarantine). In doing so, they could not come into contact with other people. The police checked compliance with the rules. Violators of the laws could be fined EUR 15-1400 in forint equivalent. ${ }^{4}$ Restrictive provisions include the complete restriction of the right of assembly. ${ }^{5}$ This severe restriction of rights is in line with global trends. Restriction alone may be justified, but it should not serve as a means of dismantling democracy (URL 2).

There was a particular restriction on freedom of expression. The false news that pops up from time to time may create misconceptions in larger masses of people. Incorrect perceptions of reality adversely affect voluntary compliance with epidemiological rules. Therefore, it became necessary to reduce the false news. As a means of doing so, the government has chosen criminal action in addition to positive campaigns. Therefore the Government ordered the punishment of a person who, during a period of the particular legal order, claims or rumors a false fact or fact in public in such a way as to obstruct or frustrate the effectiveness of the defense. However, in doing so, the legislator extends criminal liability to such a vast extent that it is neither necessary nor proportionate. The legislator uses difficult-to-interpret, inaccurate terms. Furthermore, uncertain concepts run counter to legal certainty. This keeps those who speak in public affairs during a particular legal order or even use social media doubtful, as it is not clear precisely what speeches criminal law prescribes (Domokos 2020).

Hungarian public education switched to digital curricula on April 15, 2020. The organization of education was the responsibility of the schools. Therefore, there were significant differences between schools. This scale ranged from self-study of available written curriculum to students to holding real-time online lessons.

Distance learning methods has become widespread in Russia. Circumstances forced to improve not only the technical side of distance learning, but also the development of didactic provisions for the submission and consolidation of information and progress control tools. Thus, we agree that the institutions of higher education are encouraged to focus on developing students and teachers' digital competence, creating relevant learning strategies and using appropriate tools to improve the quality of education (Zhao et al., 2021).

Despite of all criticism of distance learning, its use is justified, the rise of its popularity during the pandemic contributed to digitalization of Russian public education, which has

\footnotetext{
3 71/2020. (III.27.) Government decree

${ }^{4} 81 / 2020$. (IV. 1.) Government decree

5 46/2020. (III. 16.) Government decree
} 
retained its traditions for centuries and has not undergone major changes. We positively assess systematization of methodological and educational materials on websites, informing students about classes and failed assignments using online platforms, creating channels for posting completed written works and practice materials, real-time online lessons, school lessons on TV.

\section{Preservation of medical supplies}

To preserve and ensure the optimal use of medical supplies, the hospital command system was established, which started operating on March 30, 2020. The essence is that the chief officers of the police or the army - in addition to or instead of performing their original duties - have been assigned to head various public hospitals, state health care institutions and to perform hospital command duties. It is essential that they cannot take a position on medical matters; they do not have a decision, instruction, and control powers limited to the performance of tasks related to the preservation of hospital supplies (materials and equipment). To coordinate the activities of hospital commanders, the so-called hospital commanding staff reports to the Deputy Chief of Police, as the head of the national hospital, whose task is to coordinate the commanders' activities.

The pandemic of the coronavirus infection COVID-19 has become a serious challenge for the Russian health care system. Healthcare facilities, primarily government ones, have struggled to cope with new ways of working in the face of limited resources and an inadequate number of qualified medical personnel. At the same time, it was necessary to provide medical services to a large number of patients, mainly in hospitals. Health care providers have been forced to move from the established standards of medical practice to new protocols for health services delivery, associated with an increased risk of morbidity or mortality. Due to the lack of doctors, hospitals were forced to bring in students, residents, and doctors with specializations far removed from infectious diseases to provide medical care to COVID-19 patients. Due to a shortage of personnel, many medical workers were transferred to the created departments for the treatment of COVID-19 patients, without the necessary skills or the necessary personal protective equipment (Krasnova, 2021). In different regions, military doctors were involved in the treatment of patients infected with coronavirus within the premises of medical battalions. In total, in the first wave of the pandemic, the Russian Ministry of Defense deployed a network of 16 military medicine centers (military mobile hospitals) in 15 regions. They were designed to accomodate 1.6 thousand hospital beds.

\section{Conclusions}

Despite the different epidemiological data, the restrictive measures applied by the countries compared show a very high degree of similarity. A lack of knowledge characterized the initial period of the epidemic. No European government has had any practice in dealing with outbreaks of this magnitude. There was also a lack of extensive knowledge about the virus, its spread, symptoms, and course. States have chosen mainly the same procedure. The essential feature of this was that to deal with the dynamically changing epidemiological situation, it was considered necessary that the legal environment could be shaped dynamically enough.

Therefore, instead of the relatively slow decision-making mechanism of parliamentary democracy, parliament of Hungary has temporarily delegated much of its powers to government by promulgating an emergency legal order. 
In Russia, the legal environment was formed by the Presidential and regional executive authorities' decrees, and recommendations of the Federal Service for Surveillance on Consumer Rights Protection and Human Wellbeing (Rospotrebnadzor).

Therefore, this period, and the return from this period, was also a test of democracy in the countries under analysis. The governments of both states seem to have shown sufficient restraint.

Restrictive measures changed almost daily. Enforcement based on initial voluntary compliance was increasingly replaced by enforcement of the law by the state. With the spread of the epidemic, there has been an increasing strain on the state's law enforcement mechanisms, including law enforcement agencies in particular. The closure of shops and shopping restrictions naturally adversely affected the economy's operation, especially in the retail sector and tourism and hospitality. To comply with strict regulations, governments have not only sanctioned violations by individuals on the demand side. Supply-side companies could face even tougher sanctions.

No significant difference can be detected in the possibilities of individual defense, in the restrictions of group-forming places and events. The centralization of the health care system was also a common feature of governments.

After the significant attenuation of the first wave of the epidemic in the summer of 2020 , the special legal order in the examined countries was abolished, and parliamentary democracy was restored. However, with further waves already occurring at the time of writing, both countries have continued to stand by.

\section{References}

1. A. Balkhair, COVID-19 Pandemic: A New Chapter in the History of Infectious Diseases, Oman Medical Journal, 2 (2020). DOI: https://doi.org/10.5001/omj.2020.41

2. Z. Balla, Order Security - National Security Administration. National Security Defense As Special Administration, Curentul Juridic, The Juridical Current, Le Courant Juridique, Petru Maior University, Faculty of Economics Law and Administrative Sciences and Pro Iure Foundation, 38, 71-85 (2009)

3. A. Domokos, Certain criminal rules related to the epidemic during a special legal order, Glossa Irudicia special issue, 73-83 (2020)

4. G. M. Hadjidemetriou, M. Sasidharan, G. Kouyialis, A. K. Parlikad, The impact of government measures and human mobility trend on COVID-19 related deaths in the UK, Transportation Research Interdisciplinary Perspectives, 6 (2020)

5. K. A. Krasnova, On the criminal liability of medical workers in the context of COVID19. Criminal law: development strategy in the XXI century, XVIII International Scientific and Practical Conference. Moscow, 685-688 (2021)

6. K. Meier, T. Glatz, M. C. Guijt, M. Piccininn, M. van der Meulen, K. Atmar, Public perspectives on protective measures during the COVID-19 pandemic in the Netherlands, Germany and Italy: A survey study, PLoS ONE, 15 (8), e0236917 (2020). DOI: https://doi.org/10.1371/journal.pone.0236917

7. M. G. Reshnyak, On some problematic aspects of the activities of the investigation bodies in an emergency situation (for example, the restrictive measures associated with the coronavirus COVID-19), Emergency Law: Limits and Opportunities. Materials of the All-Russian scientific-practical conference with international participation, Irkutsk, 271-275 (2020) 
8. M. Salikov, Federalism in Russia: Current State and Emerging Trends, BRICS Law Journal, 7, 127-152 (2020). DOI: https://doi.org/10.21684/2412-2343-2020-7-4-127$\underline{152}$

9. K. Selby, M. Durand, A. Gouveia, F. Bosisio, G. Barazzetti, M. Hostettler, V. D'Acremont, A. Kaufmann, C. von Plessen, Citizen responses to government restrictions in the COVID-19 pandemic: a cross-sectional survey, Switzerland JMIR Formative Research, 20871 (2020). DOI: https://doi.org/10.2196/20871

10. T. Singhal, A Review of Coronavirus Disease-2019 (COVID-19), Indian J Pediatr, 87, 281-286 (2020). DOI: https://doi.org/10.1007/s12098-020-03263-6

11. M. Tihanyi, S. Mátyás, V. Vári, K. Krasnova, M. Volkova, Correlation between female identity in civil society and criminal repression in Hungary and Russia, Russian Law Journal, 8 (4), 92-108 (2020)

12. S. Wolf, M. Serper, L. Opsasnick, at al, Awareness, Attitudes, and Actions Related to COVID-19 Among Adults With Chronic Conditions at the Onset of the U.S. Outbreak, Annals of Inernal Medicine 21 (2020). DOI: https://doi.org/10.7326/M20-1239

13. Y. Zhao, A.M.P. Llorente, M.C.S. Gómez, Digital competence in higher education research: A systematic literature review, Computers \& Education, 168, 104212 (2021). DOI: https://doi.org/10.1016/j.compedu.2021.104212

14. SARS, Community Containment Measures and Quarantine (2021). Access mode: https://www.cdc.gov/sars/guidance/d-quarantine/index.html

15. UN Human Rights, Covid-19 and freedom of Assembly and Association (2021). Access mode:https://www.ohchr.org/EN/Issues/AssemblyAssociation/Pages/Covid19freedom Assembly.aspx 